\title{
Assessing the treatment outcome of various reproductive diseases of animals by follow-up
} monitoring in VTH, BAU

\author{
A. K. Boishakhi, R. K. Barson, N. S. Juyena, J. Bhattacharjee* \\ Department of Surgery and Obstetrics, Faculty of Veterinary Science, Bangladesh Agricultural \\ University, Mymensingh
}

\begin{abstract}
Background

Reproductive disorders have been found to be a major reason for decreased reproductive efficiency in animals. The present study was conducted to determine the effectiveness of different treatment for various reproductive diseases of domestic animals in Veterinary Teaching Hospital (VTH), Bangladesh Agricultural University (BAU), Mymensingh.
\end{abstract}

\section{Methods}

A total of 100 animals were registered for treatment during the study period. Among those 59 cattle, 9 goats and 1 turkey were treated for reproduction related diseases. On the other hand, 28 cows and 3 goats were brought for regular pregnancy diagnosis. Standard procedures were followed for the diagnosis and treatment of the diseases.

\section{Results}

Among the reproductive diseases of cattle, conception failure was $37.29 \%(\mathrm{n}=22)$, uterine infection was $33.89 \%(\mathrm{n}=20)$, anestrous was $13.56 \%(\mathrm{n}=8)$, repeat breeding was $5.08 \%(\mathrm{n}=3)$, vaginal prolapse was $3.39 \%(\mathrm{n}=2)$, pastular vulvo-vaginitis was $1.69 \%(\mathrm{n}=1)$ and ovarian hypoplasia was $1.69 \%(\mathrm{n}=1)$. Only 2 bulls $3.39 \%(\mathrm{n}=2)$ were diagnosed with posthitis. In goats, retention of placenta was $66.67 \%(n=6)$, abortion was $22.22 \%(n=2)$ and anestrous was $11.11 \%$ $(\mathrm{n}=1)$. There was one turkey with cloacal prolapse. All the animals having reproductive disease were treated in VTH. There was $93.22 \%$ improvement/effectiveness found in cows. The turkey and goats show $100 \%$ effectiveness of treatment.

\section{Conclusion}

We can conclude that the most common reproductive diseases of cattle and goats in Bangladesh are uterine infection, anestrous, conception failure, pastular vulvo-vaginitis, vaginal prolapse, repeat breeding syndrome, abortion, retention of placenta and posthitis. Any disease or disorder of the genital tract may affect the reproduction as well as the production and fertility. Therefore, it is important to be concerned about the treatment and management of the diseases of the genital tract. Careful management and treatment of these diseases will ultimately help to increase the animal's productivity in Bangladesh. The treatment given in VTH, BAU are successful for recovery.

Keywords: Animals, Reproductive disease, treatment, outcome

Copyright (C) 2018 Bangladesh Society for Veterinary Medicine. This is an open access article under the CC BY license (http://creativecommons.org/licenses/by/4.0/), which permits unrestricted use, distribution, and reproduction in any medium, provided the original author and source are credited. 


\section{Introduction}

Reproductive disorders are the major causes of reduced productivity in domestic animals. These disorders lead to reduce the reproductive efficiency as well as reduce the lifetime production of the animals (Lawson et al., 2004; Inchaisri et al., 2010). Farmers have limited knowledge about hygiene and reproductive management of domestic animals. Therefore, faulty management practices such as failure to identify oestrus correctly, poor herd management practices and record keeping are the greatest causes of reproductive disorders in a domestic animal, to mention a few (Waldner and García Guerra, 2013; Crowe et al., 2018). Common reproductive diseases of domestic female animals are anestrous, repeat breeder, uterine infection, poor heat detection, ovarian cyst, early embryonic death, retained placenta, dystocia, and pyometra. On the other hand, main reproductive diseases of male animals are orchitis, phimosis, posthitis, and balanoposthitis.

Usually, reproductive diseases are diagnosed and treated by the veterinarians on the basis of history and clinical examination. There are some reports on clinical case records from Veterinary Teaching Hospital, Bangladesh Agricultural University (Das and Hashim, 1996; Samad et al., 2002; Sarker et al., 2013), Haluaghat Upazilla Veterinary Hospital, Mymensingh (Sarker et al., 1999) and Dairy Cooperatives in Pabna district (Pharo, 1987), Chandanaish Upazilla of Chittagong district, Bangladesh (Pallab et al., 2012) and Patuakhali Science and Technology University Veterinary Clinic (Rahman et al., 2012) and also in different areas of Bangladesh (Mazid et al., 2006; Asaduzzaman et al., 2016). However, in most of the publications, they only recorded the occurrences of diseases. They did not evaluate or monitored the success or failure of the given treatments. Therefore, it is very essential to know how the farmers/owners are responding to the prescribed treatment for their animals. Farmers/owners are bringing their sick animals to Veterinary Teaching Hospital (VTH), BAU every day for treatment. Analysis of reproductive disease among the animals brought to VTH will give us a comprehensive idea about the disease occurrences. However, farmers only being prescribed here, the treatment outcome of any prescription has not been evaluated or monitored. Therefore, the present study was designed to find out the occurrence and effectiveness of different treatment of reproductive diseases of domestic animals in VTH, BAU, Mymensingh.

\section{Materials and Methods \\ Study area}

The study was carried out at Veterinary Teaching Hospital, Bangladesh Agricultural University, Mymensingh during the period from March 2017 to February 2018. One hundred sick animals were brought to the hospital for treatment of reproductive diseases. All the treated cases $(\mathrm{n}=$ 68; 59 cattle and 9 goats) of reproductive diseases and one turkey were selected for this study. Another 31 animals (28 cattle and 3 goats) were brought for routine pregnancy diagnosis. The description of each animal and owner's complaint was recorded.

\section{Data collection}

Data such as farmer's name \& address, animal species, breed, age, sex, body weight, owner's complaint, history, clinical signs, diagnosis, treatment, advice, and prognosis were entered into data collection sheet. The owners were interviewed for the history of the problem and the animals were examined clinically for diagnosis of diseases. History was taken according to the owner's complaint.

\section{Methods of diagnosis of diseases and disorders} The tentative diagnosis of diseases was performed by following standard diagnostic procedures on the basis of history, clinical signs and clinical examination of the animal such as rectal palpation or ultrasonography by the working veterinarian.

\section{Treatment given for reproductive diseases}

Specific treatment was given for specific diseases after proper diagnosis of diseases (Table 1). 
Assessing the treatment outcome of various reproductive diseases of animals

Table 1. Treatment given in VTH for the reproductive diseases

\begin{tabular}{|c|c|}
\hline Diseases & Treatment \\
\hline $\begin{array}{l}\text { Uterine infection in } \\
\text { cow }\end{array}$ & $\begin{array}{l}\text { Inj. Pronapen-40 lac vial (5), Intra-uterine infusion daily }-5 \text { days; Inj. Vita } \\
\mathrm{AD}_{3} \mathrm{E}-10 \mathrm{ml} \text { (3), IM inj. every alternate day for } 3 \text { days }\end{array}$ \\
\hline Anestrous in cow & $\begin{array}{l}\text { Inj. Vita } \mathrm{AD}_{3} \mathrm{E}-10 \mathrm{ml}(4), \mathrm{IM} \text { Inj. every alternate day for } 3 \text { days; Inj. V plex- } \\
10 \mathrm{ml}(3), \mathrm{IM} \text { Inj. every alternate day for } 3 \text { days; after } 1 \text { month, Inj. Fertilon-5 } \\
\mathrm{ml} \mathrm{IM}\end{array}$ \\
\hline $\begin{array}{l}\text { Conception failure } \\
\text { in cow }\end{array}$ & $\begin{array}{l}\text { Inj. Ovureline }-1 \mathrm{ml} \text { IM injection once only; Pow. DCP Plus-1 kg pack, } 2 \text { tsp } \\
\text { orally twice daily }\end{array}$ \\
\hline Abortion in goat & $\begin{array}{l}\text { Inj.Streptopen-0.5gm (3), IM injection for } 3 \text { days; Inj. Dextrose } 5 \%-250 \mathrm{ml}, \mathrm{IV} \\
\text { injection at a time, Inj. Oxytocin }-10 \mathrm{ml} \text { vial, } 2 \mathrm{ml} \mathrm{IM} \text { injection at a time }\end{array}$ \\
\hline $\begin{array}{l}\text { Cloacal prolapse in } \\
\text { turkey }\end{array}$ & $\begin{array}{l}\text { Tab. Ciprocin-1, as crushed tablet in } 8 \text { part and administered orally twice daily; } \\
\text { Cream Betnovet-N-1 tube, apply thrice daily in cloaca }\end{array}$ \\
\hline $\begin{array}{l}\text { Retention of } \\
\text { placenta in goat }\end{array}$ & $\begin{array}{l}\text { Inj. Streptopen- } 0.5 \mathrm{gm} \text {, IM injection for } 3 \text { days; after } 1 \text { day, Inj. Metherspen-1 } \\
\text { vial, IM Inj. at a time }\end{array}$ \\
\hline $\begin{array}{l}\text { Granular vulvo } \\
\text { vaginitis in cow }\end{array}$ & $\begin{array}{l}\text { Inj. SP Vet-2.5gm, IM injection for } 3 \text { days; Povisep, apply locally with cotton } \\
\text { once daily for } 3 \text { days; Inj. Keto Vet- } 10 \mathrm{ml} \text {, Inject } 5 \mathrm{ml} \text { IM for } 2 \text { days }\end{array}$ \\
\hline $\begin{array}{l}\text { Vaginal prolapse in } \\
\text { cow }\end{array}$ & Inj. Cal-D-Mag-200 $\mathrm{ml}$ bottle (2), inject $50 \mathrm{ml} \mathrm{SC}$ for 8 days \\
\hline $\begin{array}{l}\text { Repeat breeding } \\
\text { syndrome in cow }\end{array}$ & Inj. Fertagyl-2.5 ml, single injection \\
\hline Posthitis in bull & $\begin{array}{l}0.01 \% \text { PPM- wash daily; Inj. Streptopen- } 2.5 \mathrm{gm} \text { vial (5), } 1 \text { vial IM injection for } \\
5 \text { days; Inj. Hista-Vet-10 ml (2), } 5 \mathrm{ml} \text { IM injection for } 3 \text { days }\end{array}$ \\
\hline
\end{tabular}

Inj. Pronapen- 40 lac: Procaine Penicillin 30 lac and Benzyle Penicillin; Inj. Vita $\mathrm{AD}_{3} \mathrm{E}$ : Vitamin A $500000 \mathrm{IU}$, Vitamin D3 $75000 \mathrm{IU}$, Vitamin E 50mg per ml; Inj. Streptopen: Procaine penicillin 3lac, Benzyl penicillin 1lac, Streptomycin 500mg per 0.5g; Tab. Ciprocin: Ciprofloxacin $500 \mathrm{mg}$; Inj. Metherspen: Methyl Ergometrine Maleate $200 \mathrm{mcg} / \mathrm{ml}$; Inj. SP Vet: Penicillin G Procaine + Penicillin G Sodium + Streptomycin; Inj. Cal-DMag: Calcium Gluconate 20.8\%, Magnesium Hypophosphite 5\%, Dextrose 20\%, Chlorocresol $0.10 \%$; Inj. Fertagyl: Gonadorelin (GnRH); Inj. Hista-Vet: Pheniramine meleate BP $227.5 \mathrm{mg}$

\section{Routine check-up}

A follow-up evaluation was performed to determine the effectiveness of each treatment given. A routine checkup was carried out from the 7th day of the prescription until recovery or till next oestrus cycle, where applicable by visiting the owner's house or by mobile communication.

\section{Data analysis}

Data were entered in Microsoft Excel Spreadsheets and percentages of reproductive diseases and their treatment outcomes were calculated.

\section{Result and discussion}

Occurrence of reproduction related diseases and disorders in animals treated in VTH:

A total of 100 patients were registered having concern about reproductive problems. Among them 87 were cattle, 12 were goat and 1 was turkey. The present findings in this study revealed the occurrence of the major reproductive problems in cattle were uterine infection (33.89\%), anestrous $(13.56 \%)$, conception failure (37.29\%), pustular vulvo-vaginitis (1.69\%), vaginal prolapse $(3.39 \%)$, repeat breeding syndrome $(5.08 \%)$, ovarian' hypoplasia $(1.69 \%)$ and posthitis (1.69\%) (Table 2); Whereas in goats were abortion $(22.22 \%)$, retention of placenta $(66.67 \%)$ and anestrous (11.11\%) (Table 3), and only a single case of cloacal prolapse in turkey. 
Table 2. Occurrence of reproduction related diseases and disorders in cattle treated in VTH (March 2017 to February 2018)

\begin{tabular}{cccc}
\hline Sex & Diseases/disorders & Number & Percentage (\%) \\
\hline \multirow{4}{*}{ Female } & Conception failure & 22 & 37.29 \\
& Uterine infection & 20 & 33.89 \\
& Anestrous & 8 & 13.56 \\
& Repeat breeding & 3 & 5.08 \\
& Vaginal prolapse & 2 & 3.39 \\
Male & Pustular vulvo-vaginitis & 1 & 1.69 \\
& Ovarian hypoplasia & 1 & 1.69 \\
& Posthitis & 2 & 3.39 \\
\hline
\end{tabular}

Table 3. Occurrence of reproduction related diseases and disorders in goats treated in VTH (March 2017 to February 2018)

\begin{tabular}{ccc}
\hline Diseases/disorders & Number & Percentage (\%) \\
\hline Retention of placenta & 6 & 66.67 \\
Abortion & 2 & 22.22 \\
Anestrous & 1 & 11.11 \\
Total & 9 & 100 \\
\hline
\end{tabular}

Percentage of pregnancy diagnosis cases

Among the 100 patients, 31 animals were bought to VTH, BAU only for pregnancy diagnosis (2-6 months pregnant), where 28 were cows and 3 were goats. Nearly seventy one percent $(71.42 \%)$ cows were found pregnant and $28.57 \%$ found non pregnant (Table 4). All the goats $(n=3)$ were found pregnant (Table 4). The pregnancy diagnoses were done accurately by per rectal palpation and ultrasonography.

Table 4. Percentage of pregnancy diagnosis performed in VTH from March 2017 to February 2018.

\begin{tabular}{cccccc}
\hline Animal & $\begin{array}{c}\text { Total number } \\
(\mathrm{n}=31)\end{array}$ & Pregnant & $\begin{array}{c}\text { Percentage }(\%) \text { of } \\
\text { pregnant }\end{array}$ & Non-pregnant & $\begin{array}{c}\text { Percentage (\%) of non } \\
\text { pregnant }\end{array}$ \\
\hline Cow & 28 & 20 & 71.42 & 8 & 28.57 \\
Goat & 3 & 3 & 100 & 0 & 0 \\
\hline
\end{tabular}

Treatment outcome of different reproductive diseases of animals in VTH, BAU

treatment outcomes of different animals are We found 93.22 to $100 \%$ effectiveness (Table 5)

of the treatment given in VTH, BAU. The

Table 5: Improvement of animals after receiving effective treatment at VTH, BAU

\begin{tabular}{lccc}
\hline \multicolumn{1}{c}{ Species } & $\begin{array}{c}\text { Number of animal } \\
\text { treated }\end{array}$ & $\begin{array}{c}\text { Number of animals } \\
\text { cured }\end{array}$ & Percent cured (\%) \\
\hline Cattle & 59 & 55 & 93.22 \\
Goat & 9 & 9 & 100 \\
Turkey & 1 & 1 & 100 \\
\hline
\end{tabular}

The occurrence of uterine infection in cow was $33.89 \%$. It is higher than the prevalence rate 29.4\% reported by Moghaddam and Mamoei
(2004) in Iran and 7.6 to $11.9 \%$ reported by Faruq (2001) and Sarder et al. (2001) in selected areas of Bangladesh. Uterine infection can be caused 
by a number of factors, including the infectious agent, parturition in unhygienic condition, retained placenta, dystocia, vaginal prolapse and manual removal of placenta. Intrauterine antibiotic infusion and vitamin, mineral supplement were provided to the patients for treatment. Sheldon et al. (2003) suggested oxytetracycline for intra uterine infusion. However, Penicillin is another preferred antibiotic for treating the uterine infection as it penetrates all layers of the uterus. Most of the bacteria, which normally penetrate the endometrium and causes septicemia, were found sensitive to penicillin (Paisley et al., 1986; Smith and Risco, 2002). In the present study both penicillin and oxytetracycline was used for intrauterine infusion. All the cows with uterine infection treated in the present study were cured and conceived later on.

The percentage of anestrous was 13.56. In most of the cases, size and shape of both ovaries were found normal with few small follicles. Regressing corpus luteum was palpated in ovaries but the animal did not show sign of heat or the owner could not detect. It may be due to weak estrus sign or lack of farmers' knowledge of estrus behavior. Rahman et al (2013) recorded a $22.35 \%$ occurrence of anestrous. The higher prevalence of anestrous might be the result of variations in predisposing factors such as nutritional status, management conditions, hormonal imbalance, reproductive tract infections, and persistent corpus luteum. McDougall (2010) proposed the use of GnRH for treating anestrus cow. In this study, at first vitamin-mineral supplement and anthelmintic was provided to improve body condition and thereafter GnRH injection was given for anestrous treatment and animals were cycled later on.

In total $37.29 \%$ of cases were diagnosed as conception failure. It was assumed that the conception failure might be due to incorrect timing of artificial insemination (AI), improper heat detection or artificial insemination by unskilled AI technician (Siddiqui et al., 2013). In those cases, the owners were suggested to give GnRH injection immediately after insemination.
In some cases, they also suggested providing twice insemination in a single detected heat. All the treated cows respond well to the treatment and conceived later.

Pustular vulvo-vaginitis was found in $1.69 \%$ cases. Brenner et al., (2009) found 50\% cow affected with necrotic vulvo-vaginitis in Israel. Local wash of the area, antibiotic and antiinflammatory drugs were prescribed for treatment and the animal showed a positive response to the treatment.

The percentage of vaginal prolapse was 3.39\%, which was lower than the prevalence rate of $13.40 \%$ reported by Rahman et al (2013). Henricks et al. (1972) suggested that a combination of increased estrogens levels with decreased progesterone and increase production of relaxin, especially in the last two weeks of pregnancy may cause relaxation of the pelvic ligaments and surrounding soft tissue structures. The lower prevalence rate of vaginal prolapse may be attributed to the availability of calcium supplement in feed and less chance of the occurrence of hypocalcaemia. Baxter (2004) suggested manual replacement of the prolapsed vagina in mild cases. In the present study, two cows were found with vaginal prolapse and both of them were mild cases. They were manually corrected and subcutaneous calcium was prescribed as supportive treatment.

About 5.08\% cases of repeat breeding were observed in cows during the study period. Rahman et al. (2013) reported $19.27 \%$ and Khair et al. (2013) reported a $32.76 \%$ occurrence of repeat breeding in different areas of Bangladesh. Repeat breeding could be caused by a number of factors including sub-fertile bulls, endocrine imbalance, malnutrition, reproductive tract infections and poor management practices such as incorrect time of insemination or faulty heat detection, inappropriate semen handling and insemination techniques (Arthur et al., 1989). In addition to these, communal use of bull for natural services is also considered as contributing factors. Treatment of repeat breeding depends on the cause. In the present study, GnRH injection 
was given immediately after insemination, where no other causes were found. Whenever, any managemental faults such as health detection and incorrect insemination identified, farmers were advised how to overcome the managemental issues.

Ovarian hypoplasia was confirmed by rectal palpation and found in $1.69 \%$ cases, where both ovaries were found very small according to the age of the animals. Ovarian hypoplasia affected animal have infantile reproductive tract and never exhibit estrus. Treatment of ovarian hypoplasia included improving the feed quality, cleaning the housing and grazing the cattle frequently. When the ovarian structure gets improved, PMSG could be given intramuscularly (Darrel and Kesler, 2002; Opsomer et al., 2000). In the present study, vitamin supplement was provided. However, those animals were sold before evaluating the treatment outcome.

During the one-year study period, only one male disease $(1.69 \%)$ was found. It was posthitis. Antiseptic wash, antibiotic and anti-inflammatory drugs cured the bull.

The proportional prevalence of abortion was $22.22 \%$ in goats. Srivastava et al., (1985) reported $0.8 \%$ cases of abortion. Recently, Ahmed et al., (2008) have reported a $43.7 \%$ prevalence of abortion. The common cause of abortion is brucellosis (Mekonen et al., 2010; Rahman et al 2012). Rahman et al (2012) reported the higher prevalence of brucellosis was found in Black Bengal goats with the history of previous abortion (33.33\%). Infected animals should be treated with tetracycline, oxytetracycline, and chlortetracycline or procaine penicillin (Braun et al., 2006). In the study period, the aborted goats were prescribed for antibiotic, intravenous saline and oxytocin for bacterial infection and placental expulsion.

In the present study, $66.67 \%$ goats were diagnosed with retained placenta. Karim et al (2014) reported 50\% prevalence rate in selected areas of Bangladesh. However, the prevalence of retained placenta in goats could vary from 1.5 to
95.7\%, based on breeds, regions and different managemental conditions (Neils et al., 2009; Fthenaki et al., 2000). The retained placenta may occur as a result of premature birth, which may arise in a variety of circumstances. It is associated with abortion due to infectious causes, caesarian section and pharmacological induction of parturition (Peters and Ball, 1987). Treatment of retained placenta includes antibiotics and hormones. Some studies revealed that administration of $3 \mathrm{mg}$ of ergonomic or a similar drug developed from ergot may be more beneficial than oxytocin in cases of atonic myometrium because of its prolonged oxytocin effect (Roberts, 1986). Systemic antibiotics are believed to be beneficial in retained placenta cases where fever was also present (Drillich et al., 2006). In present study systemic antibiotic and ergot preparation were prescribed and there was satisfactory improvement in all cases of retained placenta in goats.

A total of $11.11 \%$ cases of goats were found anestrus. GnRH preparation was given for treatment in those cases. The goats later detected in heat and conceived.

During the study period, one turkey was found with cloacal prolapse with maggot infestation. At first surgical procedure was followed to remove maggots and then vitamin $\mathrm{C}$ supplement and antifungal cream were prescribed and the bird was cured.

\section{Non-response to treatment and follow up treatment}

Reproductive information of 100 animals was collected. Among them, 68 animals (59 cattle, 9 goats) were bought having the complaint of reproductive diseases. The rest were only to check pregnancy status. Among the treated animal owners, 3 cows were found not responded to the treatment and one were sold out without any treatment. Among, the animals that were bought for pregnancy diagnosis, the farmers without any further intervention sold nonpregnant animals. However, one farmer having non-pregnant cows decided for treatment intervention to make his cow pregnant in the next 
cycle. That animal was diagnosed as anestrous and treated accordingly, the animal cycled later on.

\section{Conclusions}

We can conclude that the most common reproductive diseases of cattle and goats in Bangladesh are uterine infection, anestrous, conception failure, pastular vulvo-vaginitis, vaginal prolapse, repeat breeding syndrome, abortion, retention of placenta and posthitis. Any disease or disorder of the genital tract may affect the reproduction as well as the production and fertility. Therefore, it is important to be concerned about the treatment and management of the diseases of the genital tract. Careful management and treatment of these diseases will ultimately help to increase the animal's productivity in Bangladesh.

\section{Acknowledgements}

We thank the Veterinary Teaching Hospital (VTH) authority of Bangladesh Agricultural University, Mymensingh for helping in conducting the study.

\section{Funding}

This work was supported by the Grants for Advanced Research in Science from the Ministry of Education, Government of the People's Republic of Bangladesh (LS1403) to Principal Investigator Dr. Jayonta Bhattacharjee and National Science and Technology (NST) Fellowship to DR. Abida Khanam Boishakhi.

\section{References}

1. Ahmed YF, Sokkar SM, Desouky HM and Soror AH. Abortion due to Toxoplasmosis in small ruminants. Global Veterinaria. 2008; 2(6): 337-342.

2. Arthur GH, Noakes DE and Pearson H. Veterinary Reproduction and Obsteterics. $6^{\text {th }}$ edition, Baillier Tindall, UK. 1989; 83-85.

3. Asaduzzaman KM, Bhuiyan MMU, Rahman MM, Bhattacharjee J. Prevalence of repeat breeding and its effective treatment in cows at selected areas of Bangladesh. Bangladesh Journal of Veterinary Medicine. 2016; 14 (2): 183-190.
4. Baxter K. Replacing the prolapsed bovine uterus. Veterinary Record. 2004;155:344.

5. Brenner J, Lysnyansky I, Elad D, Blum S, Bernstein M, Friedgut $\mathrm{O}$ and Rotenberg D. Granulo-pustular vulvovaginitis ("Jackal bite") an emerging disease: Mycoplasma bovigenitalium and Mycoplasma canadense infection of dairy cattle in Israel. Israel Journal of Veterinary Medicine. 2009; 64(4): 103-105.

6. Braun U, Stehle $\mathrm{C}$ and Ehrensperger $\mathrm{F}$. Clinical findings and treatment of listeriosis in 67 sheep and goat. Veterinary Record. 2006; 150(2): 38-42.

7. Crowe MA, Hostens $\mathrm{M}$ and Opsomer G. Reproductive management in dairy cows the future. Irish Veterinary Journal. 2018; 71:1.

8. Darrel $\mathrm{J}$ and Kesler. Review of estrous syncrhonization systems: CIDR inserts Proceedings, The Applied Reproductive Strategies in Beef Cattle Workshop, September 5-6, Manhattan, Kansas. 2002; 53-55.

9. Das BC and Hashim MA. Studies on surgical affections in calves. Bangladesh Veterinary Journal. 1996; 30:53-57.

10. Drillich M, Mahistedt $M$ and Reichert U. Strategies to improve the therapy of retained fetal membranes in dairy cows. Journal of Dairy Science.2006; 89(2):627-635.

11. Faruq MBH. Clinical and abattoir studies on reproductive diseases of cows in Bangladesh. MS thesis, Department of Surgery and Obstetircs, Faculty of Veterinary Science, Bangladesh Agricultural University, Mymensingh-2202, Bangladesh. 2001.

12. Fthenaki GC, Leontides LS, Amiridis GS and Saratsis P. Incidence risk and clinical features of retention of foetal membranes in goats in 28 flocks in southern Greece. Preventive Veterinary Medicine.2000; 43:85-90.

13. Henricks DM, Dickey JF, Hill JR and Johnston WE. Plasma estrogen and progesterone levels after mating, and during late pregnancy and postpartum in cows. Endocrinology. 1972; 90(5):1336-1342. 
14. Inchaisri C, Jorritsma R, Vos PL, van der Weijden GC and Hogeveen H. Economic consequences of reproductive performance in dairy cattle. Theriogenology. 2010; 74(5): 835-846.

15. Karim MR, Parvin MS, Hossain MZ, Islam MT and Hussan MT. A report on clinical prevalence of diseases and disorders in cattle and goats at the Upazilla Veterinary Hospital, Mohammadpur, Magura. Bangladesh Journal of Veterinary Medicine. 2014; 12(1): 47-53.

16. Khair A, Alam MM, Rahman AKMA, Islam MT, Azim A and Chowdhury EH. Incidence of reproductive and production diseases of cross-bred dairy cattle in Bangladesh. Bangladesh Journal of Veterinary Medicine. 2013; 11(1): 31-36.

17. Lawson LG, Bruun J, Coelli T, Agger JF and Lund M. Relationships of efficiency to reproductive disorders in Danish milk production: a stochastic frontier analysis. Journal of Dairy Science. 2004; 87 (1): 212224.

18. Mazid MA, Bhattacharjee J, Begum N, Rahman MH. Helminth parasites of the digestive system of sheep in Mymensingh, Bangladesh. Bangladesh Journal of Veterinary Medicine. 2006; 4(2): 117-122.

19. McDougall (2010). Effects of treatment of anestrous dairy cows with gonadotropinreleasing hormone, prostaglandin and progesterone. Journal of Dairy Science.2010; 93(5): 1944-1959.

20. Mekonen H, Kalayou S and Kyule M. Serological survey of bovine brucellosis in Barka and Orado breeds (Bos indicus) of western Tigray, Ethiopia. Preventive Veterinary Medicine. 2010; 94(1-2): 28-35.

21. Moghaddam AA and Mamoei M. A survey on some of the reproductive and productive traits of the buffalo in Iran, 23rd World Buiatrics Congress Qu \& Eacute, 2004; 1910.

22. Neils JS, Abdu PA and Sackey AKB. Some reproductive disorders of indigenous sheep and goats in Zaria, northern Nigeria. Nigerian Veterinary Journal. 2009; 30(1): 46-50.
23. Opsomer G, Grohn YT, Hertl J, Coryn M, Deluyker $\mathrm{H}$ and Kruif. Risk factors for post partum ovarian dysfunction in high producing cows in Belgium: A field study. Theriogenology. 2000; 53(4):841-857.

24. Paisley L, Micklesen $\mathrm{W}$ and Anderson P. Mechanisms and therapy for retained membranes and uterine infections of cows: a review. Theriogenology. 1986; 25(3):353381.

25. Pallab MS, Ullah SM, Uddin MM and Miazi OF. A cross sectional study of several diseases in cattle at Chandanaish Upazilla of Chittagong district. Scientific Journal of Veterinary Advances. 2012; 1:28-32.

26. Peters AR and Ball PJH. Reproduction in cattle. $1^{\text {st }}$ edition, Butterworth and Co. Ltd. London. 1987; 463-464.

27. Pharo HJ. Analysis of clinical case records from dairy co-operatives in Bangladesh. Tropical Animal Health and Production. 1987; 19(3): 136-142.

28. Rahman MA, Islam MA, Talukder AK, Parvin MS and Islam MT. Clinical diseases of ruminants recorded at the Patuakhali Science and Technology University Veterinary Clinic. Bangladesh Journal of Veterinary Medicine. 2012; 10(1\&2):63-73.

29. Rahman ML, Chowdhury MK, Hossain MSA, Shamsuddin M and Bhuiyan MMU. Occurence of reproductive diseases of cattle at Saturia, Manikgonj. Bangladesh Journal of Veterinary Medicine. 2013; 11(2):121125.

30. Roberts SI. Retention of placenta. Veterinary Obstetrics and Genital Diseases (Theriogenology), Woodstock, Vermont, USA.1986; p.373-388.

31. Samad MA, Islam MA and Hossain A. Patterns of occurrence of calf diseases in the district of Mymensingh in Bangladesh. Bangladesh Veterinary Journal. 2002; 36: 01-05.

32. Sarder MJU, Moni MIZ and Aktar S. Prevalence of reproductive disorders of cross breed cows in the Rajshahi district of Bangladesh. SAARC Journal of Agriculture. 2010; 8:65-75. 
Assessing the treatment outcome of various reproductive diseases of animals

33. Sarker MAS, Hashim MA, Rahman MB and Begum H. Studies on bovine lymphadenitis syndrome. Bangladesh Veterinary Journal. 1999; 10:6-8.

34. Sarker MAS, Aktaruzzaman M, Rahman AKMA and Rahman MS. Retrospective study of clinical diseases and disorders of cattle in Sirajganj District in Bangladesh. Bangladesh Journal of Veterinary Medicine. 2013;11(2): 137-144.

35. Sheldon IM, Noakes DE, Rycroft AN and Dobson $H$. The effect of intrauterine administration of estradiol on postpartum uterine involution in cattle. Theriogenology. 2003; 59(5-6):1357-71.

36. Siddiqui MA, Das ZC, Bhattacharjee J, Rahman MM, Islam MM, Haque MA, Parrish JJ and Shamsuddin M. Factors affecting the first service conception rate of cows in smallholder dairy farms in Bangladesh. Reproduction in Domestic Animals. 2013;48(3): 500-505.

37. Smith and, Risco C. Therapeutic and management options for postpartum metritis in dairy cattle. Compendium on continuing education for the practicing veterinarian. 2002; 24:74-80.

38. Srivasta AK, Patil VK and More BK. Incidence of various disorders in local angora crossbreed goats. Indian Veterinary Journal. 1985; 62:935-939.

39. Waldner CL and García Guerra A. Cow attributes, herd management, and reproductive history events associated with the risk of nonpregnancy in cow-calf herds in Western Canada. Theriogenology. 2013; 79(7): 1083-1094. 